\title{
TECNOLOGIA NA SEGURANÇA DO TRABALHO EM ROBÓTICA
}

\author{
TECHNOLOGY IN WORK SAFETY \\ Daniel Carlos Pastori - daniel5pastori@gmail.com \\ Faculdade de Tecnologia (Fatec) - Taquaritinga - SP - Brasil \\ Daniela Rodolpho - danirodolpho@yahoo.com.br \\ Faculdade de Tecnologia (Fatec) - Taquaritinga - SP - Brasil
}

DOI: 10.31510/infa.v17i2.1007

Data de publicação: 18/12/2020

\begin{abstract}
RESUMO
Quando se trata de Segurança no Trabalho é uma ferramenta indispensável para o desenvolvimento de atividades em locais que proporcione perigo, de alguma forma para o trabalhador, e ainda, proporcione uma forma eficiente e eficaz nos processos de trabalho e qualidade de vida do trabalhador. Neste sentido, este artigo tem como objetivo analisar e demonstrar informações sobre equipamentos de segurança, as tecnologias implementadas nestes equipamentos e o auxílio na prevenção e minimização dos acidentes de trabalho, em especial em recursos e tecnologia em automação e robótica utilizados nas indústrias. Tendo uma atenção especial a legislação e normativas vinculadas para estes fins. O trabalho analisou para organizar a metodologia e os resultados os principais dispositivos de segurança. Assim, apesar do trabalho com robôs atuarem de forma mais eficiente em algumas situações em linha de montagem, do que humanos, a segurança quando o trabalhador atua em espaços com máquinas é primordial e treinamento para atuação em situações de perigo também se faz necessário. E esta necessidade de cuidados será abordada nos resultados.
\end{abstract}

Palavras-chave: Máquinas; Equipamentos; Trabalhadores.

\begin{abstract}
When it comes to Safety at Work it is an indispensable tool for the development of activities in places that provide danger, in some way for the worker, and yet, provide an efficient and effective way in the work processes and quality of life of the worker. In this sense, this article aims to analyze and demonstrate information about safety equipment, the technologies implemented in this equipment and the help in the prevention and minimization of work accidents, especially in resources and technology in automation and robotics used in the industries. Paying special attention to legislation and regulations linked to these purposes. The work analyzed to organize the methodology and the results of the main safety devices. Thus, despite working with robots acting more efficiently in some situations on the assembly line, than humans, safety when the worker works in spaces with machines is paramount and training
\end{abstract}


to act in dangerous situations is also necessary. And this need for care will be addressed in the results.

Keywords: Machinery; Equipment; Workers.

\section{INTRODUÇÃO}

A base para a estruturação de segurança no que diz respeito ao trabalho em locais que usam de equipamentos pesados e estruturação robótica de empresas é dada pela Resolução 12 - Segurança no Trabalho em Máquinas e Equipamentos, aprovada pela Portaria 3.214/1978, com redação vigente dada pela Portaria da secretaria de inspeção do trabalho - SIT nº 197, de 17/12/10. Que veio de encontro ao objetivo deste artigo, que visa a visa a redução de acidentes de trabalho em maquinas no país. Este documento veio a ser redigido pelo consenso obtido em debate conduzido pelo Ministério do Trabalho e participação de representes do setor empresarial e dos trabalhadores, de vários segmentos econômicos, com a participação de outros atores sociais e governamentais (BRASIL, 1978).

A aplicação da Norma Regulamentadora 12 (NR-12) (BRASIL, 1983), requer por vezes orientações e esclarecimentos que visam a proteção da integridade física e da saúde dos trabalhadores. Neste sentido, alguns pontos devem ser delimitados na abordagem do assunto deste artigo, como as normas e requisitos técnicos necessários ao trabalho seguro com robôs industriais colaborativos (COBOTS) e robôs tradicionais em aplicações colaborativas, à luz da interpretação técnica da NR-12.

Com a emergência em busca de novas tecnologias relacionadas as indústrias, robôs e equipamentos que garantam a segurança dos envolvidos no trabalho diário com essas tecnologias se torna essencial. Neste sentido, são observadas profundas transformações nos diferentes setores industriais, ocorrendo impactos consideráveis nas condições de trabalho tanto no Brasil, como no mundo.

À medida que cresce o número de atividades automatizadas em relação às máquinas, é imprescindível os investimentos no que se refere a segurança e proteção dos trabalhadores que atuam em ambientes com a presença de máquinas. A instalação de um robô e automação robótica é necessário uma série de alterações no ambiente de uma linha de produção, como por exemplo, nos equipamentos tanto na programação, quanto na sincronização das operações, na 
comunicação entre equipamentos, e principalmente na instalação de sensores, controladores e outros dispositivos de segurança na célula robótica.

Quanto a automação, pode ser afirmado que oferece muitas vantagens no que diz respeito ao ponto de vista técnico, tais como: qualidade uniforme permanente, velocidade de trabalho alta e constante; na econômico pode ser citado: alta produtividade, substituição do dispendioso trabalho feito pelo homem por máquinas; e ainda o caráter social: livrar a humanidade da responsabilidade de atividades sujas, monótonas, difíceis ou perigosas (FESTO, 1993).

Com relação aos problemas e premissas do artigo, pode ser enfatizado que apesar das tendências de redução dos custos e outros aspectos supracitados, na utilização das novas tecnologias industriais, a montagem dos produtos são os que mais usam atividades manuais, ou seja, a que oferece mais riscos para o trabalhador. Nesta perspectiva, a automação das operações vem agregando cada vez mais o uso de robôs, e consequentemente os cuidados que delimitam a necessidade de segurança (ABREU, 2002).

O objetivo deste artigo é a apresentar e descrever os dispositivos de segurança utilizados na robótica e automação industrial, a fim de, apresentar os dispositivos de segurança aplicáveis em células robóticas. Para a realização deste artigo foram feitas análises de referencial bibliográfico fundamentado a discussão com argumentos, pesquisas e citações de autores que abordam o tema, em suas respectivas teses.

Neste sentido a inserção de robótica em trabalhos associado às pessoas, requer procedimentos e métodos que possam garantir a segurança do trabalhador, das máquinas e das instalações destes equipamentos.

\section{FUNDAMENTAÇÃO TEÓRICA}

\subsection{A indústria de manufaturas, robôs e manipuladores}

As Células flexíveis para a realização de manufatura permitindo desta forma a fabricação de diferentes produtos com características parecidas na mesma linha de montagem, assim a produção pode ser flexibilizada, onde a produção pode ser feita de acordo com a necessidade de demanda. Entretanto, em decorrência da complexidade envolvida na 
identificação de uma grande gama de partes diferentes, onde cada uma é correspondente a um determinado produto, assim, indústrias atribuem estas tarefas a operadores, pois se forem realizada tarefas por robôs implicaria em um aumento nos custos e demora a realização destas tarefas por robôs, a princípio, implicaria em uma operação mais demorada e envolveria custos maiores, em decorrência da necessidade de dispositivos utilizados para reconhecimento e a seleção de cada peça (CHIA, 2014).

Um bom exemplo desta situação, está na produção de eletrodomésticos, onde em uma mesma linha de produção podem ser produzidos diversos modelos de refrigeradores, simultaneamente. Para cada tipo deste eletrodoméstico existem estruturas semelhantes tais como: semelhantes, gabinetes internos plásticos, gabinetes externos metálicos, mesmo número de portas, mas para cada modelo existem peculiaridades, tais como volume e dimensões diferentes, ou posicionamento dos nichos internos.

\subsection{Segurança em ambientes de trabalho com robôs e máquinas}

Para que se garanta a segurança em locais de trabalho que contém com máquinas, em especial as que contam com robôs, os sistemas devem contemplar, entre os Equipamentos de Proteção Individual (EPI's), para os trabalhadores, dispositivos que garantam a segurança e proteção, sistemas de paradas seguras e restrições operacionais para pessoas que atuam nas áreas das máquinas. De acordo que a norma regulamentadora NR-12 - Segurança no Trabalho em Máquinas e Equipamentos, são considerados dispositivos de segurança "os componentes que, por si só ou interligados ou associados a proteções, reduzam os riscos de acidentes e de outros agravos à saúde" ( BRASIL, 1983, p.1).

O que tange principalmente a conceituação da NR-12 é a de o homem, que não utiliza dispositivos de segurança, não está apto a se proteger no seu meio de trabalho, assim máquinas e equipamentos têm de oferecer dispositivos para estes fins.

Em 2010 foi realizada uma revisão, em relação ao conceito de falha segura, ou seja, quando houver falha de um sistema operacional, este sistema deve passar para uma situação onde não coloque em risco o usuário. Neste sentido, a NR-12, determina o princípio de falha segura demanda que um sistema entre em um estado seguro, quando ocorrer uma falha em componente que seja relevante. Neste sentido os sistemas operacionais têm que ter dispositivos que garantam a segurança (BRASIL, 1983).

Interface Tecnológica - v. 17 n. 2 (2020) 


\section{TECNOLOGIAS E DISPOSITIVOS DE PROTEÇÃO E SEGURANÇA}

Os dispositivos, de segurança e proteção tem que ser aplicados em ambientes que a operação de máquinas oferece risco à segurança as pessoas que trabalho neste ambiente. Para a aplicação da NR-12, “consideram-se dispositivos de segurança os componentes que, por si só ou interligados ou associados a proteções, reduzam os riscos de acidentes e de outros agravos à saúde”. Para que seja considerado com a finalidade, um dispositivo de segurança, segundo o NR-12 (BRASIL, 1983, p. 1), tem que atender os seguintes requisitos:

12.38. As zonas de perigo das máquinas e equipamentos devem possuir sistemas de segurança, caracterizados por proteções fixas, proteções móveis e dispositivos de segurança interligados, que garantam proteção à saúde e à integridade física dos trabalhadores.

12.39. Os sistemas de segurança devem ser selecionados e instalados de modo a atender aos seguintes requisitos:

a) ter categoria de segurança conforme prévia análise de riscos prevista nas normas técnicas oficiais vigentes;

b) estar sob a responsabilidade técnica de profissional legalmente habilitado;

c) possuir conformidade técnica com o sistema de comando a que são integrados;

d) instalação de modo que não possam ser neutralizados ou burlados;

e) manterem-se sob vigilância automática, ou seja, monitoramento, de acordo com a categoria de segurança requerida, exceto para dispositivos de segurança exclusivamente mecânicos; e

f) paralisação dos movimentos perigosos e demais riscos quando ocorrerem falhas ou situações anormais de trabalho.

$\mathrm{Na}$ sequência deste artigo, vai ser descritos os principais dispositivos utilizados para segurança de ambientes com maquinário.

\section{Barreiras Físicas:}

As barreiras físicas visam estabelecer obstáculos físicos entre o operador do robô ou equipamento e a área de risco. Dependendo do tipo de risco, a barreira pode ser fixa, como por exemplo, grades de segurança, ou móveis, como portas. As barreiras fixas são apropriadas para situações quando há pouca ou nenhuma necessidade de acesso quanto a máquina está em operação em situação normal. A frequência do contato ou acesso a área de operação da máquina ou robô, que determina se a barreira deve ser fixa ou móvel. Outra característica que deve ser levada em consideração para que a barreira seja móvel, está na necessidade de acesso humano à área de risco a segurança, permitindo um acesso livre (CHIA, 2014). 


\section{Cortina de Luz:}

São equipamentos optoeletrônicos, que contam com unidades transmissoras e receptoras, formando uma "cortina" de luz infravermelha, sendo capazes de supervisionar uma determinada área, que são compreendidas pelas distancias entre estas duas unidades. Se a transmissão da luz infravermelha for interrompida, os sinais comutaram acusando a presença de pessoa ou objetos (WEG, 2013). As cortinas são destinadas a locais onde há a necessidade de um acesso fácil e de maneira frequente a um ponto perigoso de operação (ROCKWELL, 2013).

\section{Tapetes de Segurança:}

Os tapetes de segurança são destinados a locais para a proteção humana em áreas de operação de maquinas. Consiste em duas placas de aço que têm correntes distintas, separadas por tiras isolantes e sendo acionadas por pressão. Quando o tapete é pisado, há um contato entre estas placas que gera um sinal para o controlador do sistema (SCHMERSAL, 2013). Os tapetes de segurança, quando combinados ao controlador, aumentam a produtividade por possibilitar um acesso seguro, ao local do equipamento, mas com um menor tempo de parada, pois não há a necessidade de grandes interrupções de produção durante a operação ou a manutenção.

\section{Scanner de Área (Laser Scanner):}

São também dispositivos optoeletrônicos, que atua na proteção de pessoas ou equipamentos, onde são capazes de detectar objetos dentro do seu campo de detecção. Sua operação é baseada na reflexão de luz e seus princípios. São emitidos pulsos de laser infravermelhos em uma área determinada de até 190 graus, onde os receptores recebem a reflexão de luz, determinando desta forma, a distância e posição de um determinado objeto, quando detectados anomalias no campo de verificação, há o sinal para a interrupção da máquina do local (CHIA, 2014).

\section{Chaves de Paradas de Emergência:}

De acordo com a NR-12, as máquinas devem ter uma ou mais chaves de paradas de emergência, onde pelo seu acionamento possa evitar perigo latente ou existente. Tais dispositivos devem estar em locais de fácil acesso e observação, mantendo-os sempre 
desobstruídos. Outra característica necessárias destes dispositivos, está no fato de terem de prevalecer sobre todos os outros comandos. Devem ser ainda, mantidos por outros meios de segurança e ser usado como medida auxiliar, não podendo ser assim, alternativas aos outros meios de segurança. A chave quando acionada, tem de resultar na retenção do acionador, onde a reversão do acionamento tenha de ser feita de forma intencional, como por exemplo, ter que girar para que seja liberado (CHIA, 2014).

\section{Chaves de Intertravamento:}

Existem basicamente dois tipos de chaves, as mecânicas e as magnéticas. A primeira se baseia-se no contato de um operador de forma mecânica, normalmente com um lingueta mecânica, onde é fixada em barra móvel, onde o dispositivo é fixado em barreira física. Com relação ao custo, é inferior ao segundo tipo, mas tem algumas desvantagens onde é a exigência de um correto alinhamento entre as partes e é passível de desgastes. O segundo tipo é baseado em imã que deve ser fixado na proteção móvel e dispositivo na barreira fixa. Neste tipo, não há desgaste mecânico, apresentando a não necessidade de alinhamento. As chaves de intertravamento de segurança deve ter contato de abertura positiva, que é acionado a uma barreira móvel é aberta. O sistema de abertura positiva, mesmo que ocorra falha interna da chave, como uma colagem, por exemplo, a abertura do contato NF e o desligamento do circuito conectado a chave seja garantida. Deve-se ainda, que as chaves devem ser dotadas de acionadores codificadas, para que não ocorram problemas com o sistema (CHIA, 2014).

\section{Consolidação das Leis Trabalhistas (CLP) de Segurança:}

A NR-12 prevê que os sistemas de segurança devem ser mantidos sobre uma vigilância automática de acordo, com a categoria de segurança requerida. As interfaces de segurança ou mesmo os comandos elétricos que são classificados no NR-12, são dispositivos de monitoramento, que verificam interligação, posição, funcionamento dos outros dispositivos do sistema e impedem as ocorrências de falhas que promovem a perda da função de segurança. Tradicionalmente a utilização de CLPs convencionais nos sistemas de segurança, tem relação às redundâncias, por exemplo, utilizando dois CLPs conectados a entradas e saídas também redundantes, o que garante as rotinas relacionas a segurança, mesmo que haja falha de um dos dispositivos, sensores ou atuadores. Para este tipo de equipamento, que tradicionalmente são atribuídos redundância requerem softwares customizados exigindo mais tempos para o 
desenvolvimento das soluções e ainda, exigindo espaços físicos para equipamento e fiações (CHIA, 2014).

\section{DISCUSSÃO}

As máquinas e as tecnologias na atualidade vêm substituindo o homem em diversas funções, onde as complexidades das funções e as legislações para a segurança do trabalhador, evoluíram na mesma proporção. Com a NR-12 são dimensionadas as normatizações que devem ser levadas em consideração, para que haja a melhora das tecnologias de segurança e como deve ser suas aplicações, principalmente quando o trabalhador divide seu local de atuação com máquinas ou robôs. Esta norma ou toda a tecnologia envolvida para a segurança não diminuem a zero os riscos dos acidentes, ou seja, atenção e tecnologia tem de andar juntos (BRASIL, 1983).

Na mesma forma que aumenta a mecanização do trabalho, há a necessidade de que se aumente também os itens e formas de manter a segurança dos trabalhadores.

Destaque-se o disposto no item 12.51 da NR-12:

12.51 Durante a utilização de proteções distantes da máquina ouequipamento com possibilidade de alguma pessoa ficar na zonade perigo, devem ser adotadas medidas adicionais de proteçãocoletiva para impedir a partida da máquina enquanto houver pessoas nessa zona (BRASIL, 1983, p. 2).

A legislação e esforços no desenvolvimento de itens de segurança têm evoluindo muito, com aumento da produtividade, sem prejuízo do fator segurança. Os vários itens e equipamentos de segurança é um investimento que deve crescer, junto às empresas, juntamente com os planejamentos de expansão, principalmente quando esta expansão conta com o aumento da mecanização da produção (CHIA, 2014).

Ainda em relação a segurança necessária para aplicação de robôs em automação industrial existe também como documento norteador publicado em 2016 a International Organization for Standardization ISO/TS 15066 é uma especificação técnica para segurança de sistemas robóticos colaborativos. É um documento de apoio às normas ISO 10218-1 e ISO 10218- 2, e visa à redução de restrições na interação entre humanos e robôs, bem como a orientação para operações colaborativas entre estes. (NBR 14153, 2013; Associação Brasileira de Normas Técnicas (ABNT) NBR ISO 10218-1, 2016; ABNT NBR ISO 10218-2, 2018).

Neste sentido, Sistemas robóticos industriais geralmente tendem a separar pessoas de robôs, de modo a evitar danos e lesões. Porém, com os recentes avanços tecnológicos, há uma 
tendência crescente de unir de forma segura a potência e a precisão dos robôs com a inteligência para a resolução de problemas dos humanos, o que poderá aumentar de forma significativa a produtividade da indústria.

Assim, a relação e coordenação de esforços visam que haja uma integração cada vez maior entre trabalhadores e máquinas da forma mais segura possível. E inovações tecnológicas em robótica industrial crescem proporcionalmente com os dispositivos de segurança.

\section{METODOLOGIA}

A metodologia utilizada foi de revisão bibliográfica, onde foi analisado artigos e autores que abordaram de forma sistêmica em seus trabalhos e análises definem os procedimentos de segurança adotados em ambientes de trabalho, onde há atuação do pessoas e robôs. Assim, verificar quais dispositivos e sistemas de segurança são mais eficazes neste sentido.

\section{CONCLUSÃO}

A máquina vem substituindo o trabalho humano, aumentando em funcionalidade e complexidade, consequentemente as legislações de proteção dos trabalhadores tem se tornado mais rigorosa, uma vez que o risco de acidentes também aumentou. Face que foi exposto notase a preocupação em se ter um avanço tecnológico e industrial na área de robótica, caminha em paralelo ao aumento das tecnologias voltadas a segurança dos trabalhadores.

Além, das preocupações com a legislação e normas vigentes que atendam a necessidade e aspectos relacionados à segurança, que determinam necessidades específicas para cada realidade e funcionalidade.

Outro fator que deve ser ressaltado é a de que há necessidade de treinamento dos trabalhadores que atuam nestes setores, e com atenção ao funcionamento e acionamentos dos dispositivos de segurança.

Portanto, a proposta em demonstrar e analisar os dispositivos de segurança que são necessários para que atuação dos profissionais envoltos em atividade que utilizem máquinas e robôs foi dimensionada. E também como se aplica e como funciona cada um destes dispositivos. Assim, contribuindo para menos acidentes de trabalhos. 


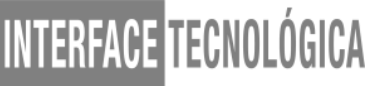

\section{REFERÊNCIAS}

ABREU, P. Robótica Industrial. Porto: Universidade do Porto, 2002. Disponível em: $<$ http://paginas.fe.up.pt/ aml/maic_files/aplicacoes.pdf >. Acesso em: 10 out2020.

BRASIL. Associação Brasileira De Normas Técnicas. NBR 14153 - Segurança de Máquinas Partes de sistemas de comando relacionados à segurança. Rio de Janeiro, 2013.

Associação Brasileira De Normas Técnicas. ABNT NBR ISO 10218-1: robôs e dispositivos robóticos: requisitos de segurança para robôs industriais: parte 1: robôs. Rio de Janeiro: 2016.

Associação Brasileira De Normas Técnicas. ABNT NBR ISO 10218-2: robôs e dispositivos robóticos: requisitos de segurança para robôs industriais: parte 2: sistemas robotizados e integração. Rio de Janeiro: 2018.

Ministério do Trabalho. Portaria $\mathrm{n}^{\circ} 3214$, de 08 de junho de 1978. Aprova as Normas Regulamentadoras- NR - do Capítulo V, Título II, da Consolidação das Leis do Trabalho, relativas a Segurança e Medicina do Trabalho. Brasília. DOU de 06/07/1978. Seção I-Parte I, pág. 10.423.

Ministério do Trabalho. Portaria MTb n 3124, de 08 de junho de 1978. NR - 12 Segurança no Trabalho em Máquinas e Equipamentos e suas atualizações. Brasília. DOU de 14/06/83. Disponível em: <http://www.mte.gov.br/seg_sau/nr_12_texto.pdf>. Acesso em 12 out 2020 .

CHIA, I.M.C. Segurança em célula Robótica. Universidade Tecnológica Federal do Paraná. Programa de Pós-graduação. Especialização em Automação Industrial. Curitiba 2014.

Disponível em:

$<$ http://repositorio.roca.utfpr.edu.br/jspui/bitstream/1/2368/1/CT_CEAUT_IV_2014_01.pdf $>$. Acesso em: 10 out 2020. 


\section{WTEEREAEETECENOLOGGCA}

FESTO D. Fundamentos da robótica. São Paulo: Festo, 1993.

ROCKWELL Automation. Produtos de Segurança. 2013 Disponível em:

$<$ http://ab.rockwellautomation.com/pt/Safety>. Acesso em: 10 out 2020.

SCHMERSAL DO BRASIL. Catálogo Tapetes de Segurança. Disponível em:

$<$ https://www.schmersal.com.br/produtos/seguranca/produto/tapete-de-seguranca/> Acesso em: 10 out 2020 .

WEG. Cortinas de Luz de Segurança. Disponível em: < http://www.weg.net/br/Produtos-eServicos/Controls/Linha-Safety/Cortinas-de-Luz-de-Seguranca>. 2013. Acesso em: 24 set 2020 . 